The Lancet Infectious Diseases Volume 6, Issue 1 , January 2006, Pages 39-45

doi:10.1016/S1473-3099(05)70325-X

Copyright (c) 2006 Elsevier Ltd All rights reserved.

\title{
Mathematical modelling: a tool for hospital infection control
}

\section{Dr H Grundmann ${ }^{\mathrm{a}, \mathrm{c}, *}$ and B Hellriegel ${ }^{\mathrm{b}, \mathrm{c}}$}

${ }^{a}$ National Institute of Public Health and the Environment, Bilthoven, and Department of Medical Microbiology, University of Groningen, Groningen, Netherlands

${ }^{b}$ Institute for Medical Statistics and Epidemiology, TU Munich, Munich, Germany

${ }^{\mathrm{C}}$ Institute for Advanced Study, Berlin, Germany

* Correspondence to: Dr H Grundmann, Institute for Advanced Study, Wallotstrasse 19, D-14193 Berlin, Germany. Tel +31 (0)30 2744239 261; fax +31(0)302742971

\section{Summary}

Health-care-associated infections caused by antibiotic-resistant pathogens have become a menace in hospitals worldwide and infection control measures have lead to vastly different outcomes in different countries. During the past 6 years, a theoretical framework based on mathematical models has emerged that provides solid and testable hypotheses and opens the road to a quantitative assessment of the main obstructions that undermine current efforts to control the spread of health-care-associated infections in hospitals and communities. We aim to explain to a broader audience of professionals in health care, infection control, and health systems administration some of these models that can improve the understanding of the hidden dynamics of health-care-associated infections. We also appraise their usefulness and limitations as an innovative research and decision tool for control purposes.

\section{Introduction}

Health-care-associated infections are characterised by pathology related to the presence of infectious agents or their products as a result of exposure to healthcare procedures. Among other transmissible agents (fungi, viruses, parasites, prions, etc), health-care-associated infections are often caused by bacteria, which have frequently acquired resistance to one or more antimicrobial agent. Importantly, these bacteria have the ability to colonise human beings for prolonged periods, and colonised patients may disseminate these nosocomial pathogens both during and after their hospital stay. Any means to control healthcare-associated infections will need to adapt to the changing nature of medicine and health-care delivery and demand a thorough understanding of the underlying dynamics of health-care-associated infections with respect to their ecology, epidemiology, and economic ramifications. Best practice in this modern sense means adopting evidence-based and cost-effective methods. Mathematical models help identify factors responsible for observed patterns of occurrence and may provide theoretical guidelines for the design of efficient countermeasures. The purpose of this review is to explain recent quantitative models that describe 
the dynamics of health-care-associated infections in mathematical terms to a broader audience of professionals in health care, infection control, and health system administration.

Most models that describe the transmission dynamics of nosocomial pathogens divide the host population in the community or hospital into compartments of individuals who are either susceptible to colonisation or infection, or colonised or infected (figure). ${ }^{1}$ These compartment models make specific assumptions about the transmission process of bacteria between susceptible and colonised patients (either infected or asymptomatic carriers). Although some of these compartment models describe the ecological consequences of antimicrobial consumption on the competition between susceptible and resistant bacterial strains, and may thus be of interest to prescribers, ${ }^{6,7,8,9,10}$ and 11 we concentrate on epidemiological models, which investigate the transmission of resistant pathogens in the context of institutional settings and that have direct implications on physical infection control strategies-eg, contact isolation, cohorting, hand hygiene, and patient referral practices.

(A) Model of indirect "vector-mediated" transmission between patient-health-care worker (HCW)-patient (Ross-Macdonald model ${ }^{2}$ and 3 ) exploring the effects of hand washing, staff cohorting, and antibiotic restriction. Patients (colonised by resistant bacteria or uncolonised) are admitted to a hospital where they interact with health-care workers (contaminated with resistant bacteria or uncontaminated). Adapted with permission from references 3 and 4. (B) Model with direct patientpatient transmission between randomly mixing individuals (mass action assumption) investigating the effect of an isolation unit. Individuals (colonised or uncolonised) are admitted to a hospital, discharged, and readmitted at a high or low rate. Adapted with permission from reference 5. (C) Metapopulation model for a multi-institutional setting with hospitals $(\mathrm{H})$, long-term care facilities (LTCFs), and their catchment population (community). Individuals (colonised or uncolonised) migrate between the different institutions and the community due to admissions, discharges, and referrals. 
The Lancet Infectious Diseases Volume 6, Issue 1 , January 2006, Pages 39-45

A

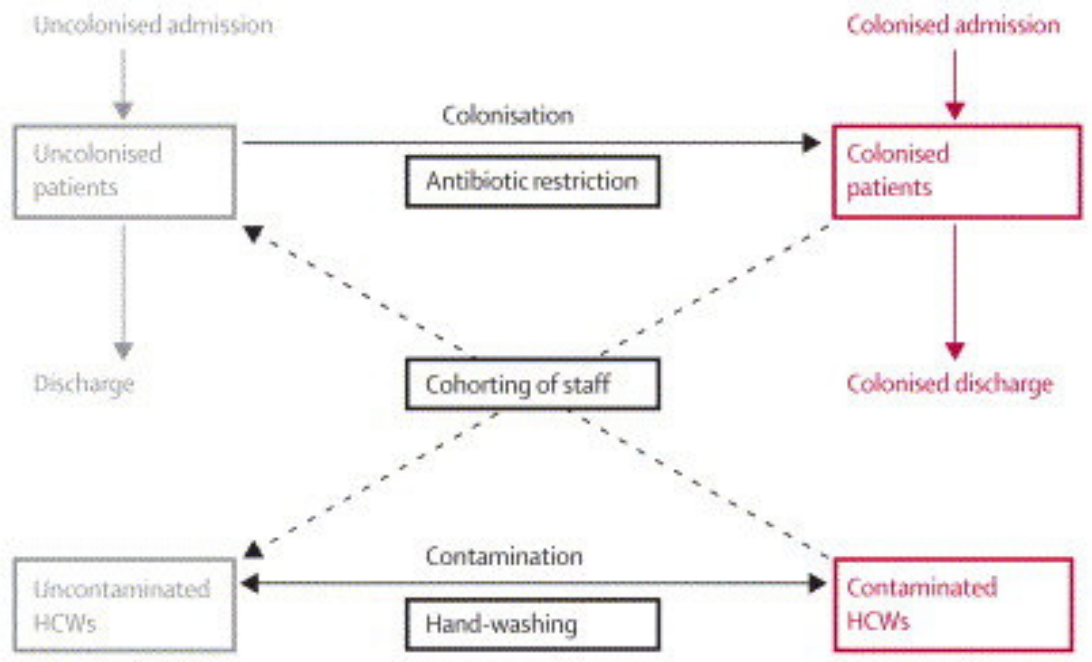

B

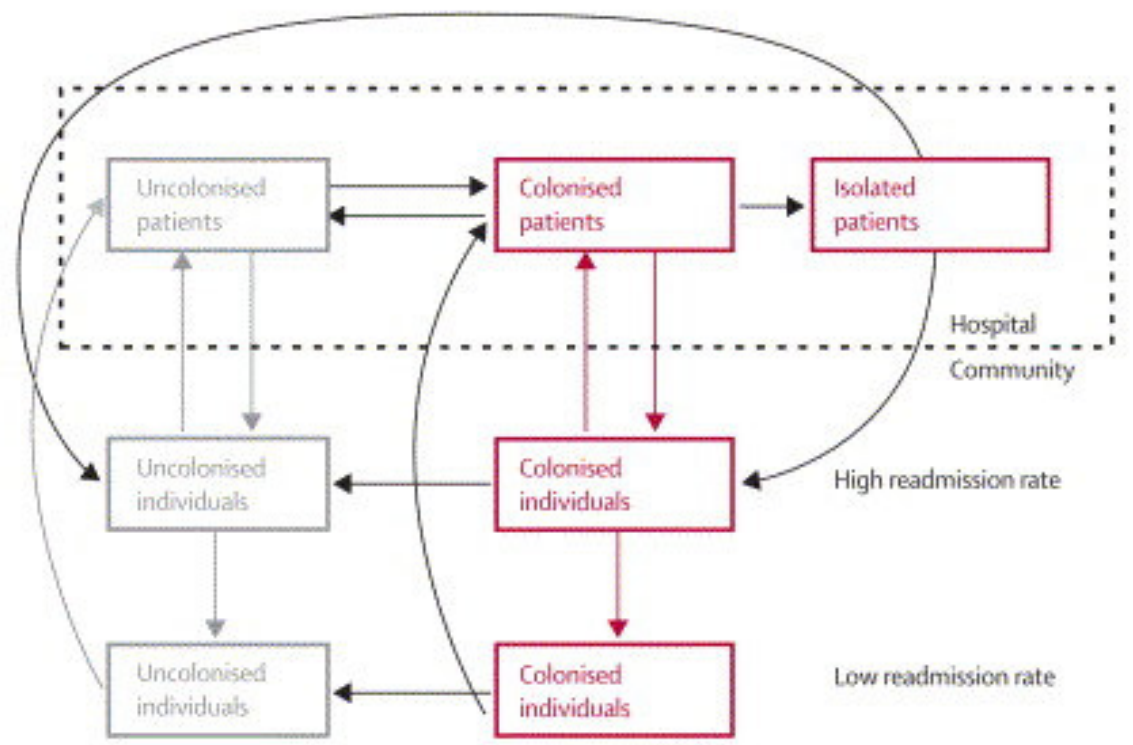

c

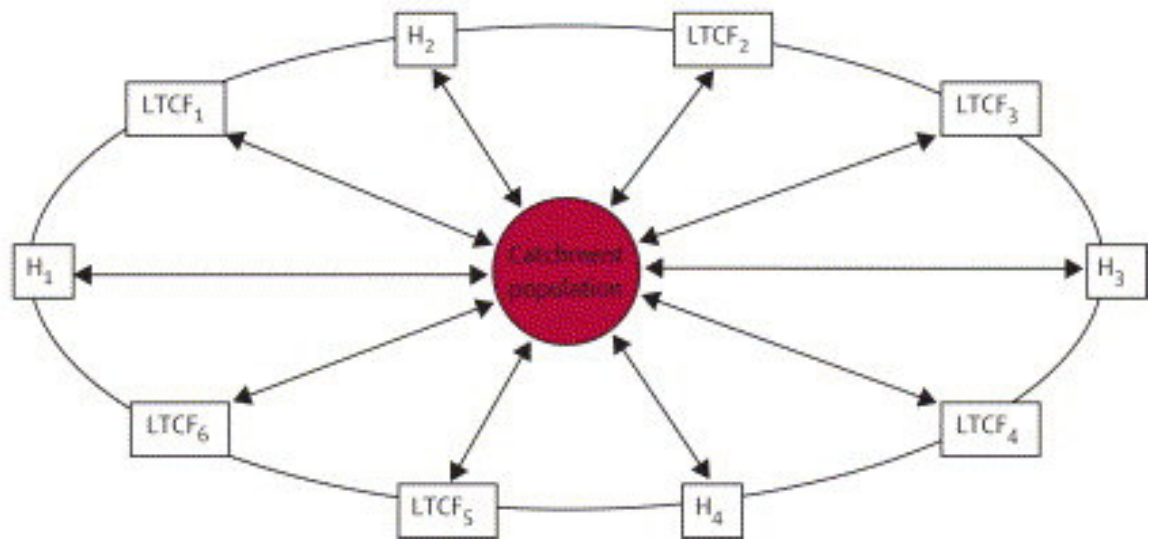

Figure. Flow diagrams for the types of models discussed in the text 


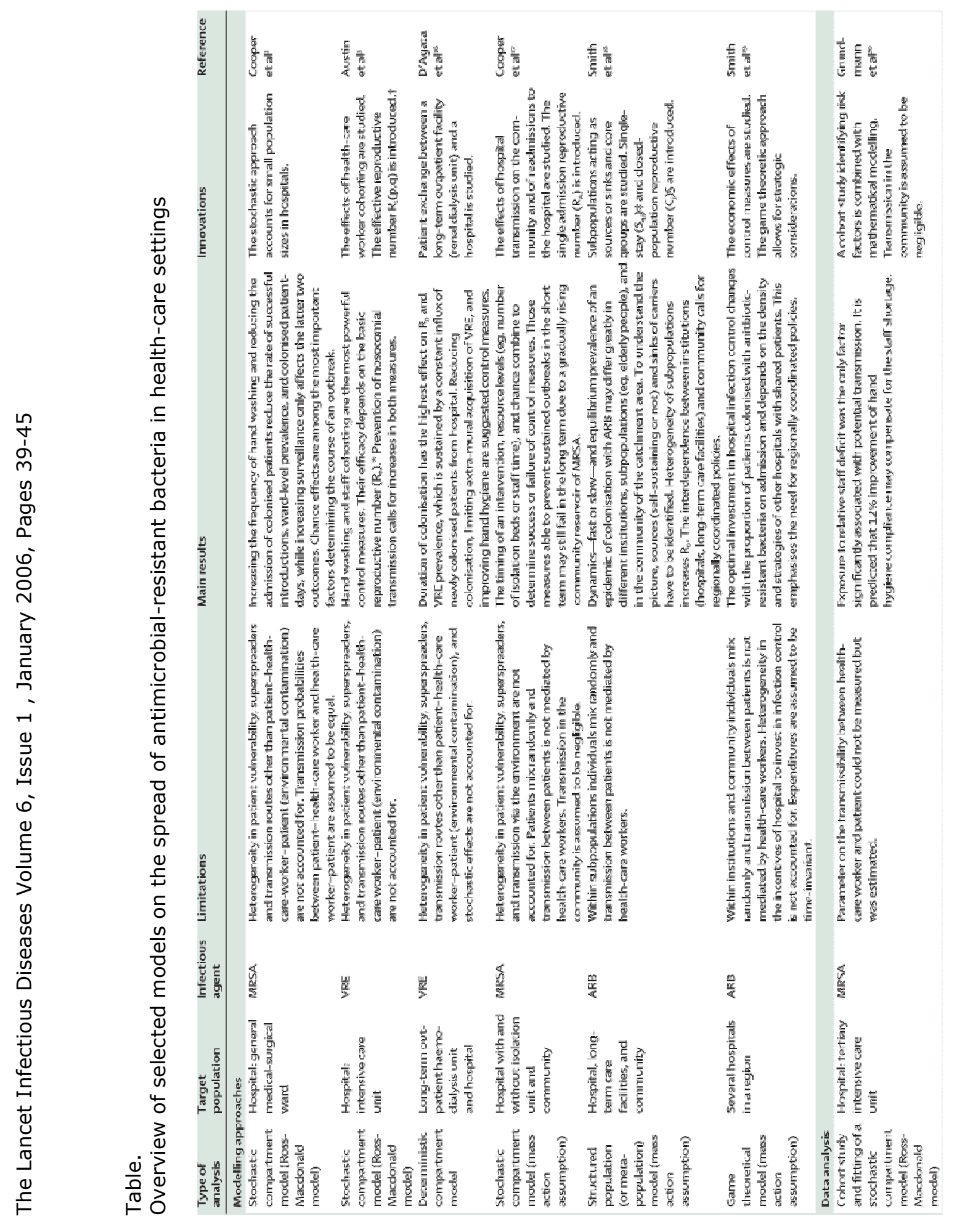




\begin{tabular}{|c|c|c|c|c|c|c|}
\hline Type of analysis & $\begin{array}{l}\text { Target } \\
\text { population }\end{array}$ & $\begin{array}{l}\text { Infectious } \\
\text { agent }\end{array}$ & Limitations & Main results & Innovations & Reference \\
\hline \multicolumn{7}{|c|}{ Modelling approaches } \\
\hline \begin{tabular}{|l|} 
Stochastic \\
compartment \\
model (Ross- \\
Macdonald model)
\end{tabular} & $\begin{array}{l}\text { Hospital: } \\
\text { general } \\
\text { medical- } \\
\text { surgical ward }\end{array}$ & MRSA & $\begin{array}{l}\text { Heterogeneity in patient vulnerability, } \\
\text { superspreaders and transmission } \\
\text { routes other than patient-health-care- } \\
\text { worker-patient (environmental } \\
\text { contamination) are not accounted for. } \\
\text { Transmission probabilities between } \\
\text { patient-health-care worker and } \\
\text { health-care worker-patient are } \\
\text { assumed to be equal. }\end{array}$ & $\begin{array}{l}\text { Increasing the frequency of hand washing } \\
\text { and reducing the admission of colonised } \\
\text { patients reduce the rate of successful } \\
\text { introductions, ward-level prevalence, and } \\
\text { colonised patient-days, while increasing } \\
\text { surveillance only affects the latter two } \\
\text { outcomes. Chance effects are among the } \\
\text { most important factors determining the } \\
\text { course of an outbreak. }\end{array}$ & $\begin{array}{l}\text { The stochastic approach } \\
\text { accounts for small } \\
\text { population sizes in } \\
\text { hospitals. }\end{array}$ & $\begin{array}{l}\text { Cooper et } \\
\mathrm{al}^{2} \underline{ }\end{array}$ \\
\hline \begin{tabular}{|l|} 
Stochastic \\
compartment \\
model (Ross- \\
Macdonald model)
\end{tabular} & $\begin{array}{l}\text { Hospital: } \\
\text { intensive care } \\
\text { unit }\end{array}$ & VRE & $\begin{array}{l}\text { Heterogeneity in patient vulnerability, } \\
\text { superspreaders, and transmission } \\
\text { routes other than patient-health-care } \\
\text { worker-patient (environmental } \\
\text { contamination) are not accounted for. }\end{array}$ & $\begin{array}{l}\text { Hand washing and staff cohorting are the } \\
\text { most powerful control measures. Their } \\
\text { efficacy depends on the basic reproductive } \\
\text { number }\left(R_{0}\right) \text {. }^{*} \text { Prevention of nosocomial } \\
\text { transmission calls for increases in both } \\
\text { measures. }\end{array}$ & $\begin{array}{l}\text { The effects of health-care } \\
\text { worker cohorting are } \\
\text { studied. The effective } \\
\text { reproductive number } \\
\mathrm{R}_{E}(p, q) \text { is introduced. }{ }^{ \pm}\end{array}$ & Austin et $\mathrm{al}^{3}$ \\
\hline $\begin{array}{l}\text { Deterministic } \\
\text { compartment } \\
\text { model }\end{array}$ & $\begin{array}{l}\text { Long-term } \\
\text { outpatient } \\
\text { haemo-dialysis } \\
\text { unit and } \\
\text { hospital }\end{array}$ & VRE & $\begin{array}{l}\text { Heterogeneity in patient vulnerability, } \\
\text { superspreaders, transmission routes } \\
\text { other than patient-health-care } \\
\text { worker-patient (environmental } \\
\text { contamination), and stochastic effects } \\
\text { are not accounted for. }\end{array}$ & $\begin{array}{l}\text { Duration of colonisation has the highest effect } \\
\text { on } R_{0} \text { and VRE prevalence, which is sustained } \\
\text { by a constant influx of newly colonised } \\
\text { patients from hospital. Reducing colonisation, } \\
\text { limiting extra-mural acquisition of VRE, and } \\
\text { improving hand hygiene are suggested } \\
\text { control measures. }\end{array}$ & $\begin{array}{l}\text { Patient exchange between } \\
\text { a long-term outpatient } \\
\text { facility (renal dialysis unit) } \\
\text { and a hospital is studied. }\end{array}$ & $\begin{array}{l}\text { D'Agata et } \\
\text { al } 16^{16}\end{array}$ \\
\hline \begin{tabular}{l|} 
Stochastic \\
compartment \\
model (mass \\
action assumption)
\end{tabular} & $\begin{array}{l}\text { Hospital with } \\
\text { and without } \\
\text { isolation unit } \\
\text { and } \\
\text { community }\end{array}$ & MRSA & $\begin{array}{l}\text { Heterogeneity in patient vulnerability, } \\
\text { superspreaders, and transmission via } \\
\text { the environment are not accounted } \\
\text { for. Patients mix randomly and } \\
\text { transmission between patients is not } \\
\text { mediated by health-care workers. } \\
\text { Transmission in the community is } \\
\text { assumed to be negligible. }\end{array}$ & $\begin{array}{l}\text { The timing of an intervention, resource levels } \\
\text { (eg, number of isolation beds or staff time), } \\
\text { and chance combine to determine success or } \\
\text { failure of control measures. Those measures } \\
\text { able to prevent sustained outbreaks in the } \\
\text { short term may still fail in the long term due } \\
\text { to a gradually rising community reservoir of } \\
\text { MRSA. }\end{array}$ & $\begin{array}{l}\text { The effects of hospital } \\
\text { transmission on the } \\
\text { community and of } \\
\text { readmissions to the } \\
\text { hospital are studied. The } \\
\text { single admission } \\
\text { reproductive number }\left(\mathrm{R}_{\mathrm{A}}\right) \\
\text { is introduced. }\end{array}$ & 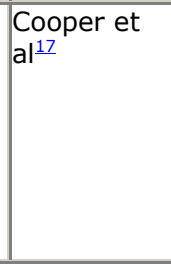 \\
\hline \begin{tabular}{|l|} 
Structured \\
population (or \\
meta-population) \\
model (mass \\
action assumption)
\end{tabular} & $\begin{array}{l}\text { Hospital, long- } \\
\text { term care } \\
\text { facilities, and } \\
\text { community }\end{array}$ & ARB & $\begin{array}{l}\text { Within subpopulations individuals mix } \\
\text { randomly and transmission between } \\
\text { patients is not mediated by health- } \\
\text { care workers. }\end{array}$ & $\begin{array}{l}\text { Dynamics-fast or slow-and equilibrium } \\
\text { prevalence of an epidemic of colonisation } \\
\text { with ARB may differ greatly in different } \\
\text { institutions, subpopulations (eg, elderly } \\
\text { people), and in the community of the } \\
\text { catchment area. To understand the picture, } \\
\text { sources (self-sustaining or not) and sinks of } \\
\text { carriers have to be identified. Heterogeneity }\end{array}$ & $\begin{array}{l}\text { Subpopulations acting as } \\
\text { sources or sinks and core } \\
\text { groups are studied. Single- } \\
\text { stay }\left(\mathrm{S}_{g, \mathrm{j}}\right)^{\ddagger} \text { and closed- } \\
\text { population reproductive } \\
\text { number }\left(\mathrm{C}_{\mathrm{j}}\right)^{\S} \text { are } \\
\text { introduced.- }\end{array}$ & $\begin{array}{l}\text { Smith et } \\
\text { al } \underline{18}\end{array}$ \\
\hline
\end{tabular}




\begin{tabular}{|c|c|c|c|c|c|c|}
\hline Type of analysis & $\begin{array}{l}\text { Target } \\
\text { population }\end{array}$ & \begin{tabular}{|l|}
$\begin{array}{l}\text { Infectious } \\
\text { agent }\end{array}$ \\
\end{tabular} & Limitations & Main results & Innovations & Reference \\
\hline & & & & $\begin{array}{l}\text { of subpopulations increases } R_{0} \text {. The } \\
\text { interdependence between institutions } \\
\text { (hospitals, long-term care facilities) and } \\
\text { community calls for regionally coordinated } \\
\text { policies. }\end{array}$ & & \\
\hline $\begin{array}{l}\text { Game theoretical } \\
\text { model (mass } \\
\text { action assumption) }\end{array}$ & $\begin{array}{l}\text { Several } \\
\text { hospitals in a } \\
\text { region }\end{array}$ & ARB & $\begin{array}{l}\text { Within institutions and community } \\
\text { individuals mix randomly and } \\
\text { transmission between patients is not } \\
\text { mediated by health-care workers. } \\
\text { Heterogeneity in the incentives of } \\
\text { hospital to invest in infection control is } \\
\text { not accounted for. Expenditures are } \\
\text { assumed to be time-invariant. }\end{array}$ & $\begin{array}{l}\text { The optimal investment in hospital infection } \\
\text { control changes with the proportion of } \\
\text { patients colonised with anitbiotic-resistant } \\
\text { bacteria on admission and depends on the } \\
\text { density and strategies of other hospitals with } \\
\text { shared patients. This emphasises the need } \\
\text { for regionally coordinated policies. }\end{array}$ & $\begin{array}{l}\text { The economic effects of } \\
\text { control measures are } \\
\text { studied. The game } \\
\text { theoretic approach allows } \\
\text { for strategic } \\
\text { considerations. }\end{array}$ & $\begin{array}{l}\text { Smith et } \\
\text { al }{ }^{\frac{19}{9}}\end{array}$ \\
\hline \multicolumn{7}{|c|}{ Data analysis } \\
\hline $\begin{array}{l}\text { Cohort study and } \\
\text { fitting of a } \\
\text { stochastic } \\
\text { compartment } \\
\text { model (Ross- } \\
\text { Macdonald model) }\end{array}$ & $\begin{array}{l}\text { Hospital: } \\
\text { tertiary } \\
\text { intensive care } \\
\text { unit }\end{array}$ & MRSA & $\begin{array}{l}\text { Parameter on the transmissibility } \\
\text { between health-care worker and } \\
\text { patient could not be measured but } \\
\text { was estimated. }\end{array}$ & $\begin{array}{l}\text { Exposure to relative staff deficit was the only } \\
\text { factor significantly associated with potential } \\
\text { transmission. It is predicted that } 12 \% \\
\text { improvement of hand hygiene compliance } \\
\text { may compensate for the staff shortage. }\end{array}$ & $\begin{array}{l}\text { A cohort study identifying } \\
\text { risk factors is combined } \\
\text { with mathematical } \\
\text { modelling. Transmission in } \\
\text { the community is assumed } \\
\text { to be negligible. }\end{array}$ & $\begin{array}{l}\text { Grundmann } \\
\text { et al } 20\end{array}$ \\
\hline
\end{tabular}

The relation between antibiotic use and prevalence of antibiotic resistance and competition between sensitive and resistant bacteria are not accounted for in these models. ARB=antibiotic-resistant bacteria; MRSA=meticillin-resistant

Staphylococcus aureus; VRE=vancomycin-resistant enterococci.

${ }^{*} R_{0}$ is the average number of secondary cases generated by one primary case.

${ }^{\dagger} R_{E}(p, q)$ depends on the probability, $p$, of health-care workers complying with hand washing and the probability, $q$, of health-care workers having cohorted contacts.

${ }^{\ddagger} S_{g, j}$ is the average number of new cases generated by a particular carrier of a particular group $g$ in subpopulation $j$ during a single visit when resistance is rare. $R_{0}$ then is the average over all groups and subpopulations.

${ }^{\S} C_{j}$ is the average number of new cases generated by a particular carrier in subpopulation $j$ when prevalence is low and migration ignored. 
Mechanistic models attempt to reduce the complexity of systems, making them more accessible to specific questions, and to explore scenarios under varying conditions. To this end, models for health-care-associated infections take into account only those factors that are considered relevant to disease transmission and influence or constrain the dynamic spread of nosocomial pathogens. Whether the model predictions (eg, the possible effect of infection control measures) are qualitative or quantitative depends on the nature and availability of empirical data. In case quantitative data are lacking a coarser model may be preferable. Finally, a model has to be validated by comparing its results with qualitative observations or quantitative data from the real world. When devising a model to explain an observed pattern of health-care-associated infections, three factors need to be considered: (1) the natural history and the duration of colonisation and infection, (2) the transmission routes and the implications of different routes on the spread of the pathogens, and (3) the host behaviour and demography. With this knowledge a simple flow diagram describing the changes in the host population caused by pathogen exposure can be constructed. Basically, such a model consists of three parts, as follows.

First, the outcome, which is the item of interest. The outcome is dependent on several parameters and their influence is explained by the model. Direct outcome variables are the number (or proportion) of susceptible or colonised/infected individuals at any time point or the expected prevalence at the time when a pathogen has established stable endemicity (equilibrium prevalence). Since the proportion of infected individuals could actually be measured in natural populations or data may be available from surveillance studies, these numbers can be compared with the model outcomes to validate the model. An indirect and very intuitive outcome is the average number of secondary cases caused by introducing a single primary case into a susceptible population. In the absence of control measures, this number is termed basic reproduction number $\left(R_{0}\right)$ and defines the intrinsic transmissibility of an infectious agent. The effective reproduction number $\left(R_{E}\right)$ is the average number of secondary cases when not everyone in the population is susceptible, or, for instance, after control measures have been introduced. If $R_{E}$ exceeds one, the infection spreads, if it is smaller than one the infection dies out. Naturally, the aim of all infection control measures is to reduce $R_{E}$ and prevent pathogens from becoming established by keeping $R_{E}$ below one.

Second is the structure, which is the theoretical framework (the flow diagram) that describes the perceived transmission dynamics and aims to explain the outcome. The structure consists of the arrangement of compartments (ie, states) through which the population of interest passes and arrows that link these compartments and indicate the directions of flow between them (figure). In mathematical terms this structure is represented by a set of differential equations that describe the rate change in each compartment.

Third are the parameters, which are the actual determinants that drive the system-eg, the rates of referral between hospitals or wards, the average length of stay of susceptibles and colonised/infectious cases, the probabilities of direct or health-care worker-mediated contact between patients, or infection control measures such as the cohorting rates, hand hygiene, and decontamination effectiveness that diminish transmission. 


\section{Single ward models}

The mathematical models first published for hospital epidemiology were concerned with the transmission dynamics between patients in a single hospital ward. 2,3,16 and 21 Although deterministic models were an obvious starting point ${ }^{16}$ and

${ }^{21}$ it was quickly understood that, due to the typically small number of patients in single wards such as intensive care units with ten to 20 beds, chance or stochastic effects will be of importance. ${ }^{2,3}$ and 4

Two papers focus on stochastic effects (panel). ${ }^{2}$ and 3 Both use a model that describes the transmission of malaria by mosquito vectors known as the RossMacdonald model. ${ }^{1}$ The analogy in the transmission process is obvious. The contaminated hands of health-care workers who move between patients act as the vector. In this framework, transmission requires two contacts to complete the cycle: first, between donor patient and health-care worker and second, between health-care worker and recipient patient. Hence the contact rate enters the equation to calculate $R_{E}$ twice and thus becomes a quadratic term. Therefore, limiting patient-health-care worker contacts as well as enforcing hand hygiene, gloving, and gowning will reduce transmission to and from health-care workers and will have a much larger effect on the overall dynamics than eradicating patient colonisation, which contributes only linearly.

Cooper and colleagues ${ }^{2}$ investigated the effects of limiting the admission of colonised patients and of improving hand hygiene of health-care workers on the prevalence of meticillin-resistant Staphylococcus aureus (MRSA) (figure, A). As expected from the low numbers of patients in the ward ( 20 beds), the authors showed that the stochastic behaviour of transmission events indeed results in a high variability of predicted outcomes. Model results were therefore presented as the mean behaviour of 1000 simulations together with the corresponding $95 \%$ CIs. Introduction and transmission of MRSA resulted in an s-shaped increase of mean MRSA prevalence only limited by the availability of free beds in the ward. The assumption that transmission rates of patient-to-health-care worker and health-care worker-to-patient are equal implies that even modest changes in transmissibility have a disproportionate effect on MRSA prevalence and on colonised-patient days per year, a measure related to the economic costs. Therefore, the model suggests an important effect of hand hygiene on MRSA spread. However, the model assumes that hand hygiene reduces contamination to zero, which can only be expected if hand disinfection procedures are carried out properly. Finally, the model led to the conclusion that increasing the average length of stay for all patients to block beds or directly reducing the proportion of colonised new admissions to the ward would represent effective management strategies to further reduce the incidence of outbreaks. The former intervention seems to be unrealistic since keeping patients for longer generates increased costs for the hospital, whereas the latter may have the undesirable effect of relocating the MRSA load and costs to less selective hospitals in the same region.

Another study, published by Austin and colleagues ${ }^{3}$ around the same time, likewise investigated the effects of health-care procedures and antibiotic restriction on the prevalence of vancomycin-resistant enterococci (VRE) in an intensive care unit (figure, A). The investigators parameterised their model with surveillance data from a previous study carried out in an intensive care unit with a highly endemic VRE problem. As already concluded by Cooper and colleagues, ${ }^{2}$ hand hygiene turned out to be the most powerful control measure. Given the reported compliance rates, eradication by hand hygiene will, however, be much more difficult when nosocomial transmission is intense (high $\mathrm{R}_{0}$ ). Alternatively, limiting the number of patients a health-care worker cares for (staff cohorting) 
turns out to be another powerful control measure. For example, if half of the nurses return to the same patient for each successive contact, then transmission will be reduced by up to $50 \%$. By introducing threshold concepts, the authors were then able to define the conditions-ie, the level of cohorting or hand hygiene above which further transmission in the intensive-care unit cannot sustain endemic VRE levels in the absence of continuous introduction of colonised patients.

Following on from this a posteriori parameterised model, Grundmann and coworkers ${ }^{20}$ used a cohort approach to test the previous model by Austin and colleagues ${ }^{3}$ in the context of MRSA transmission under actual intensive-care-unit conditions. The prospective nature of this study allowed for accurate parameter measurements, which are essential for fitting the model to real time data. Concomitantly, classic regression analysis permitted the comparison of the effect of staffing levels on the occurrence of clustered versus sporadic cases of MRSA in the same intensive-care unit. An illustration of the daily number of MRSA cases, allows for the comparison between observed prevalence and model prognoses, which proved to be extremely accurate in predicting the actual MRSA dynamics over the 1-year observation period. Moreover, there is agreement between the statistical and modelling approach in that staffing levels crucially influence the transmission of MRSA in the ward, lending support to the frequently voiced notion ${ }^{22}$ that clusters of MRSA patients mainly occur when the patient-to-staff ratio drops below a critical threshold.

\section{Single hospital and community studies}

Based on a systematic review of isolation policies in hospital management of MRSA, the first comprehensive hospital-community model was published by Cooper and colleagues. ${ }^{5}$ and 17 The model set out to determine the long-term effects on MRSA prevalence when taking admission and discharge practices of MRSA patients into account. In a second step, the effect of introducing a contained isolation ward on the spread of MRSA in hospital and community was explored (figure, B). The resulting model explains the effects of hospital transmission on community prevalence and of reintroduction of MRSA carriers with high and low readmission rates into the hospital. The model suggests that two factors-long intervals between repeated readmission and long duration of colonisation-may fully explain the slow increase of MRSA in hospitals seen in many European countries. ${ }^{23}$ These factors imply that substantial increases in MRSA endemicity may go unnoticed for several years, even with a relatively high $\mathrm{R}_{0}$ of $1 \cdot 27 . .^{5}$

Cooper and colleagues ${ }^{15}$ also introduced the concept of the single-stay reproduction number $\left(R_{A}\right)$, which corresponds to the average number of cases generated per single hospital admission, as a new outcome variable. It has been shown in intensive-care units that during routine practice and in the absence of major outbreaks, patient-to-patient transmission is rather infrequent and most nosocomial infections are, in fact, the consequence of autoinfection from endogenous colonisation. ${ }^{24}$ Based on these observations and theoretical considerations ${ }^{25}$ and 26 it is reasonable to expect $R_{A}$ to stay below one on average hospital wards. But even with $\mathrm{R}_{\mathrm{A}}$ less than one, sporadic clusters of cases can occur. Only their size will tend to increase the closer $R_{A}$ approaches unity. ${ }^{27}$ Therefore, the first introduction of MRSA into an MRSA-free hospital-community collective may cause an occasional outbreak or will (more likely) result in stochastic extinction even without effective infection-control protocols in place. Moreover, the model suggests that MRSA prevalence can reach either a high or a low equilibrium for a wide range of parameter values (bistability). Consequently, 
The Lancet Infectious Diseases Volume 6, Issue 1 , January 2006, Pages 39-45

the timing of an intervention, the resource levels (eg, available isolation beds or staff time), and chance effects combine to determine success or failure of control measures. Even if control policies can prevent sustained outbreaks in the short term, they may still fail in the long term when overall $R_{E}$ exceeds one due to frequent colonised readmission from a community with gradually rising MRSA reservoirs.

\section{Models including multiple hospitals and communities}

Smith and colleagues ${ }^{18}$ elegantly extended previous models by considering an entire health-care collective consisting of a finite number of subpopulations in hospitals, long-term care facilities, and the community served by these institutions (figure, C). In this metapopulation model, individuals move at certain rates between subpopulations that differ with respect to their composition, length of stay, and the frequency of transmission. This approach allows the study of the influence of core groups, a concept that was first introduced in the context of modelling sexually transmitted diseases. ${ }^{28}$ A core group represents a subset of individuals who have a higher than usual prevalence and propensity to spread certain infectious agents and who are either more vulnerable or share a (uncommon) behaviour. With respect to health-care-associated infections caused by antibiotic resistant organisms (eg, MRSA, VRE), core groups are typically patients with comorbidities or chronic diseases and frequently involve elderly people. Such patients are often hospitalised and frequently exposed to antibiotics and invasive interventions, and have a higher contact rate with health-care workers.

The total prevalence in the catchment population is largely determined by the number and composition of subpopulations (hospitals, long-term care facilities, and their proportion of core group members) and depends on whether and how strongly subpopulations act as sources or sinks of nosocomial pathogens. ${ }^{18}$ Here a subpopulation is called source if, in the absence of exchange with other subpopulations, the number of colonised or infected patients increases and results in an epidemic-ie, the closed-population reproduction number exceeds one. Moreover, the model distinguishes between self-sustaining sources where $R_{A}$ is larger than one and dependent sources with $R_{A}$ less than one. Through referral and readmission, antimicrobial resistant pathogens can persist even in a catchment population without a self-sustaining source but at least one dependent source. Heterogeneity introduced by higher hospitalisation frequencies of core group members or differences in length of stay between hospitals and long-term care facilities can greatly increase the overall $R_{E}$ for the entire system. Carriage and transmission within the community where people stay much longer than in hospitals may have a crucial role, even when the transmission dynamic is very slow. Thus, one critical control variable is the proportion of asymptomatic carriers circulating among hospitals and health-care institutions that serve a common catchment population. This variable is, however, not the product of any individual hospital's decision but the consequence of the collective action of all institutions in the community.

Following up on this work, Smith and colleagues ${ }^{19}$ provided a strategic framework that couples the biological and economic aspects of infection control in single hospitals and in multi-institutional settings. Their model suggests that while the costs associated with resistance increase with the proportion of colonised admissions, the benefits of infection control for individual hospitals may decrease. In other words, the optimal economic solution for individual hospital shifts to an increased spending on control of resistant bacteria with low transmissibility until colonisation on admission becomes too large, eventually prompting a do-nothing 
policy. As their game theoretical approach shows, the incentive to give up all infection-control efforts (and to free-ride on the investment of others) may even be higher in a multi-institutional setting where infection-control policies of other hospitals determine the proportion of (asymptomatic) carriers in the catchment population. Consequently, a conflict ensues between the economic decision of individual hospitals versus the common goal of community-wide management of health-care-associated infections caused by antibiotic resistant bacteria such as MRSA and VRE. Herein lies the potential for a classic dilemma epitomised by Hardin's tragedy of the commons. ${ }^{29}$

\section{Mathematical models for epidemiology: strengths and limitations}

There is no doubt that the value of "classic" epidemiological investigations lies in its "quasi-experimental" nature, which allows assessment of the importance of certain variables under real world conditions. For example, the effect of a risk factor on a particular outcome can be measured. The quantity that best explains the observed variation of the outcome is the parameter characterising this relation.

The mathematical compartment models described here permit purely theoretical investigations. The value of these virtual experiments is that system parameters can be freely modified, the magnitude of their effect on the outcome calculated, and thus the sensitivity of the system to certain changes of parameters quantified. Moreover, while classic epidemiological studies are constrained by operational, financial, or ethical demands, mathematical models have the freedom to consider interventions that would otherwise not be feasible. Also, the fact that the quantitative nature of mathematical models exposes their underlying hypotheses to higher analytical scrutiny seems to be advantageous because it enhances the possibility to reject them through falsification. On the other hand, mathematical models depend heavily on the plausibility of their structure and simplifying assumptions and on the availability of estimates for their (main) parameters. The latter, in turn, limits model complexity as a lack of suitable data argues for a coarser model. Consequently, collecting reliable longitudinal data on key parameters in hospitals, long-term care facilities, and the community will allow for more realistic models with increased predictive value. For a model to prove valid, its results have to be at least qualitatively consistent with observed patterns and if possible should reasonably fit quantitative empirical data. Eventually, mathematical models force upon the investigator a detailed reflection of the process he or she intends to understand and this, by itself, is invaluable when trying to unravel the complex texture of reality. This implies that classic epidemiological approaches and mathematical modelling can complement each other in a most profitable way-one taking an empirical, the other an explorative stance. When combined, they provide excellent guidance for interventions.

\section{Conclusions}

Mathematical models, although fraught with simplifying assumptions, have the capacity to provide an insight into the forces that drive the epidemiology of health-care-associated infections and antimicrobial resistance in hospitals and communities. The past 5 years have seen a steady evolution and improvement of mathematical models that are able to describe, quantify, and capture the dynamics of transmission and spread of pathogens that can cause health-careassociated infections, most of which are associated with multiple antimicrobial resistance. Stepwise and constantly building on the achievements of preceding publications, a theoretical framework has emerged that puts forth some solid and testable hypotheses on the spread of health-care-associated infections and 
antimicrobial resistance. The following factors turn out to be main ingredients that undermine efforts to control antimicrobial resistance and health-care-associated infections in hospitals and explain the stealth behaviour and slow but relentless increase of antimicrobial resistance as a major public-health threat: (1) low virulence, and as a consequence (2) long-term asymptomatic carriage; (3) chance effects affecting transmission; (4) transient carriage (eg, in health-care workers); (5) core group behaviour; (6) heterogeneity of health-care institutions serving common catchment populations; (7) control failure in single institutions; and (8) rational market decisions in multi-institutional settings. Accepting the explanatory validity of the presented studies, the models emphasise the need for concerted regional strategies involving all partners in the health-care arena and they clearly show that any single control effort made by individual hospitals can be compromised by the decisions of others. The model results also call for multiinstitutional studies able to test the suggested hypotheses and for national consensus plans informed by intervention studies coercing stakeholders into active contribution to infection control as executed by Scandinavian countries and the Netherlands.

\section{Search strategy and selection criteria}

Relevant publications and studies were identified by searches in PubMed and ISI Web of Science taking into account the bibliographies of all identified publications. Search terms were "mathematical" and/or "model" or "transmission dynamics" or "game theory" and ("hospital" or "health-care-associated" or "nosocomial" or "resistance" or "infection control"). Articles dealing with ecological considerations such as competition between antibiotic-sensitive and antibiotic-resisistant pathogens were not included.

\section{Acknowledgments}

We would like to thank the Institute for Advanced Study in Berlin (Wissenschaftskolleg zu Berlin) for awarding the authors a fellowship for the academic year 2004-2005, and two anonymous referees for their helpful comments. 


\section{References}

1 RM Anderson and RM May, Infectious diseases of humans: dynamics and control, Oxford University Press, Oxford (1991).

2 BS Cooper, GF Medley and GM Scott, Preliminary analysis of the transmission dynamics of nosocomial infections: stochastic and management effects, J Hosp Infect 43 (1999), pp. 131-147.

3 DJ Austin, MJM Bonten, RA Weinstein, S Slaughter and RM Anderson, Vancomycin-resistant enterococci in intensive-care hospital settings: transmission dynamics, persistence, and the impact of infection control programs, Proc Natl Acad Sci USA 96 (1999), pp. 6908-6913.

4 DJ Austin and RM Anderson, Studies of antibiotic resistance within the patient, hospitals and the community using simple mathematical models, Phil Trans R Soc Lond B 354 (1999), pp. 721-738.

5 BS Cooper, SP Stone and CC Kibbler et al., Modelling of transmission dynamics and economics of control of MRSA by patient isolation, Health Technol Assess 7 (2003), pp. 53-74.

6 E Massad, S Lundberg and HM Yang, Modeling and simulating the evolution of resistance against antibiotics, Int J Biomed Comput 33 (1993), pp. 65-81.

$7 \mathrm{~S}$ Bonhoeffer, M Liptsitch and BR Levin, Evaluating treatment protocols to prevent antibiotic resistance, Proc Natl Acad Sci USA 94 (1997), pp. 12106-12111.

8 DJ Austin, M Kakehashi and RM Anderson, The transmission dynamics of antibiotic-resistant bacteria: relationship between resistance in commensal organisms and antibiotic consumption, Proc $\mathrm{R}$ Soc Lond B 264 (1997), pp. 1629-1638.

9 M Lipsitch, CT Bergstrom and BR Levin, The epidemiology of antibiotic resistance in hospitals: paradoxes and prescriptions, Proc Natl Acad Sci USA 97 (2000), pp. 1938-1943.

10 CT Bergstrom, M Lo and M Lipsitch, Ecological theory suggests that antimicrobial cycling will not reduce antimicrobial resistance in hospitals, Proc Natl Acad Sci USA 1001 (2004), pp. 13285-13290.

11 GF Webb, EM D'Agata, P Magal and S Ruan, A model of antibiotic-resistant bacterial epidemics in hospitals, Proc Natl Acad Sci USA 102 (2005), pp. 13343-13348.

12 BR Levin, M Lipsitch and S Bonhoeffer, Population biology, evolution and infectious diseases: convergence and synthesis, Science 283 (1999), pp. 806-809.

13 B Hellriegel, Immunoepidemiology-bridging the gap between immunology and epidemiology, Trends Parasitol 17 (2001), pp. 102-106.

14 L Hufnagel, D Brockmann and T Geisel, Forecast and control of epidemics in a globalized world, Proc Natl Acad Sci USA 101 (2004), pp. 15124-15129.

15 KF Smith, AP Dobson, FE McKenzie, LA Real, DL Smith and ML Wilson, Ecological theory to enhance infectious disease control and public health policy, Frontiers in Ecology and the Environment 3 (2005), pp. 27-39.

16 EM D'Agata, MA Horn and GF Webb, The impact of persistent gastrointestinal colonization on the transmission dynamics of vancomycin-resistant enterococci, J Infect Dis 185 (2002), pp. 766-773.

17 BS Cooper, GF Medley and SP Stone et al., Methicillin-resistant Staphylococus aureus in hospitals and the community: Stealth dynamics and control catastrophes, Proc Natl Acad Sci USA 27 (2004), pp. 10223-10228.

18 DL Smith, J Dushoff, EN Perencevich, AD Harris and SA Levin, Persistent colonization and the spread of antibiotic resistance in nosocomial pathogens: resistance is a regional problem, Proc Natl Acad Sci USA 101 (2004), pp. 3709-3714.

19 DL Smith, SA Levin and R Laxminarayan, Strategic interactions in multi-institutional epidemics of antibiotic resistance, Proc Natl Acad Sci USA 102 (2005), pp. 3153-3158. 
The Lancet Infectious Diseases Volume 6, Issue 1 , January 2006, Pages 39-45

20 H Grundmann, S Hori, B Winter, A Tami and DJ Austin, Risk factors for the transmission of methicillin-resistant Staphylococus aureus in an adult intensive care unit: fitting a model to the data, J Infect Dis 185 (2002), pp. 481-488.

$21 \mathrm{~V}$ Sébille, S Chevret and AJ Valleron, Modeling the spread of resistant nosocomial pathogens in an intensive-care unit, Infect Control Hosp Epidemiol 18 (1997), pp. 84-92.

22 M Farrington, C Trundle, C Redpath and L Anderson, Effects on nursing workload of different methicillin-resistant Staphylococcus aureus (MRSA) control strategies, J Hosp Infect 46 (2000), pp. $118-122$.

23 EW Tiemersma, SL Bronzwaer and O Lyytikäinen et al., Methicillin-resistant Staphylococcus aureus in Europe, 1999-2002, Emerging Infect Dis 10 (2004), pp. 1627-1634.

24 H Grundmann, S Bärwolff and F Schwab et al., How many infections are caused by patient-topatient transmission in intensive care units?, Crit Care Med 33 (2005), pp. 946-951.

25 I Pelupessy, MJM Bonten and O Diekmann, How to assess the relative importance of different colonization routes of pathogens within hospital settings, Proc Natl Acad Sci USA 99 (2002), pp. 56015605.

26 B Cooper and M Lipsitch, The analysis of hospital infection data using hidden Markov models, Biostatistics 5 (2004), pp. 223-237.

27 CP Farrington, MN Kanaan and NJ Gay, Branching process models for surveillance of infectious diseases controlled by mass vaccination, Biostatistics 4 (2003), pp. 279-295.

28 HW Hethcote and JA Yorke, Gonorrhea transmission dynamics and control, Springer, Berlin (1984).

29 G Hardin, The tragedy of the commons, Science 162 (1968), pp. 1243-1244. 


\section{Glossary of terms used}

\section{Deterministic model}

These models apply when there is a strict pre-determined relation between variables and outcome or when the dynamics for populations can be sufficiently described by the average behaviour of individuals. Consequently, parameters assume fixed values (compare with stochastic model).

\section{Mass-action principle}

Originally derived from physical chemistry by William Hamer in 1906, the mass-action principle states that the number of future cases is proportional to the product of the number of existing infectious cases times the susceptibles in a population, an assumption that assumes homogenous mixing of people.

\section{Metapopulation model}

Derived from spatial ecology, these models account for the heterogeneity and complexities resulting from the separation of different subpopulations that exchange individuals in a defined way-eg, different health-care institutions that refer patients between each other.

\section{Parameter}

A parameter is a factor of influence modifying an outcome that, depending on the setting, can be measured or estimated (parameter value). In compartment models parameters are often rates-eg, the transmission rate-that affect the movement of subjects between different compartments.

\section{$\mathbf{R}_{\mathbf{0}}$}

The basic reproduction number is the number of secondary cases originating by transmission from a primary infectious case introduced into a totally susceptible population-ie, in the absence of immunity, infection control measures, and already colonised or infected individuals.

\section{$\mathbf{R}_{\mathbf{E}}$}

The effective or net reproduction number is the number of secondary cases resulting from one primary case when one or more of the following holds: (1) part of the population is not susceptible due to natural resistance or immunity, (2) part of the population is protected by infection control measures, or (3) part of the population cannot become infected due to pre-existing colonisation/infection.

\section{Stochastic model}

These models take into account that phenomena are hardly ever deterministic-eg, as in Ohm's law. Stochastic models allow for the fact that disease transmission is a discrete and largely random event and that individuals are heterogeneous. In fact, random fluctuations can drive pathogens and infections to extinction (stochastic extinction); this is particularly true when populations are small (as in the case of a hospital ward-eg, an intensive care unit). To account for stochasticity, simulations can be done. In such simulations the events (eg, transmissions) do not occur at a fixed rate (ie, the average behaviour in deterministic models) but with a probability inferred by the parameter value. On the basis of a large number of simulations, the mean and variance describe the average behaviour of the model. 